\title{
Refleks Nasokardiak yang Disebabkan oleh Pemasangan Selang Nasogastrik: Laporan Kasus
}

\author{
Sidharta Manggala ${ }^{1,2^{*}}$, Luther Napitupulu' ${ }^{1}$, Septianto Halim ${ }^{1}$
}

1. Rapid Response Team RSUPN Dr. Cipto Mangunkusumo, Jakarta

2. Departemen Anestesiologi dan Terapi Intensif, Fakultas Kedokteran Universitas Indonesia, RSUPN Dr. Cipto Mangunkusumo, Jakarta, Indonesia

*penulis korespondensi

DOI: $10.55497 /$ majanestcricar.v38i2.190

\begin{abstract}
ABSTRAK
Refleks nasokardiak merupakan bagian dari refleks trigeminokardiak. Refleks nasokardiak dapat menyebabkan bradikardia dan hipotensi karena adanya manipulasi terhadap cabang nervus trigeminus yang berada pada rongga hidung. Pemasangan selang nasogastrik adalah prosedur medis yang umum dilakukan dan dapat menyebabkan iritasi pada rongga hidung, Laporan kasus ini menggambarkan adanya kejadian bradikardia, hipotensi, dan penurunan kesadaran yang terjadi segera setelah pemasangan selang nasogastrik pada seorang pasien laki-laki berusia 46 tahun dengan diagnosis pneumonia, tuberkulosis paru, sepsis, hipoksemia, dan hiperkapnia. Refleks nasokardiak harus dicurigai sebagai etiologi terjadinya refleks vagal pada pasien setelah pemasangan selang nasogastrik dan kejadian ini harus diantisipasi dengan baik terutama pada pasien dengan kondisi kritis. Dengan adanya keterbatasan referensi pada topik ini, penelitian lanjutan untuk kejadian ini perlu dilakukan
\end{abstract}

Kata Kunci: refleks nasokardiak; refleks vagal; selang nasogastrik 


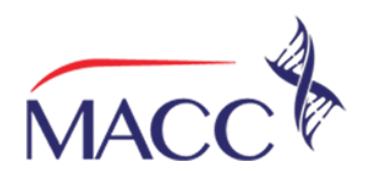

\title{
Nasocardiac Reflex Caused by Nasogastric Tube Insertion: A Case Report
}

Sidharta Manggala ${ }^{1,2^{*}}$, Luther Napitupulu ${ }^{1}$, Septianto Halim ${ }^{1}$

1. Rapid Response Team Dr. Cipto Mangunkusumo National General Hospital, Jakarta, Indonesia

2. Departement of Anesthesiology and IntensifCare, Faculty of Medicine, Universitas Indonesia, Dr. Cipto Mangunkusumo National General Hospital, Jakarta, Indonesia

*corresponding author

\begin{abstract}
Nasocardiac reflex is known as a variant of trigeminocardiac reflex. Nasocardiac reflex may lead to bradycardia and hypotension following manipulation of the branch of trigeminal nerve in the nasal cavity. Feeding tube insertion is a common medical procedure that may cause irritation in nasal cavity. This case report describe a case of immediate bradycardia, hypotension, and unconsciousness after insertion of feeding tube on a 46-years-old male diagnosed with pneumonia, lung tuberculosis, sepsis, hypoxemia, and hypercapnia. With the presence of vagal reflex symptoms when feeding tube is inserted, the nasocardiac reflex must be considered as an etiology and anticipated especially in a critically ill patient. Due to limited references for this topic, further investigation is needed.
\end{abstract}

Keywords: nasocardiac reflex; vagal reflex; feeding tube 


\section{PENDAHULUAN}

Nasocardiac reflex (NCR) pertama kali dilaporkan oleh Baxandall dan Thorn pada tahun 1988 dan selanjutnya mulai didefinisikan oleh pada ahli sebagai variasi dari trigeminocardiac reflexes (TCR) ${ }^{1,2}$ Meskipun demikian, refleks nasokardiak tidak umum dibahas dan dilaporkan sebagai variasi TCR karena jarang terjadi.1 Refleks ini dapat mempengaruhi sistem jantung dan paru karena adanya perubahan yang cepat dari aktivitas nervus vagus yang dapat menyebabkan kejadian tidak diinginkan. ${ }^{2}$

NCR pertama kali dilaporkan pada pasien yang menjalani operasi hidung dimana terjadi iritasi dinding hidung yang disebabkan karena instrumen bedah. Pemasangan selang nasogastrik adalah prosedur medis yang sering dilakukan pada pasien dan dapat menyebabkan iritasi pada dinding rongga hidung. Beberapa komplikasi yang dapat terjadi selama pemasangan selang nasogastrik sudah banyak dilaporkan, namun belum banyak yang membahas tentang refleks vagal yang terjadi pada prosedur tersebut. ${ }^{3}$ Kejadian ini merupakan kejadian yang langka namun dapat berakibat fatal pada pasien. Laporan kasus ini bertujuan untuk mendiskusikan kejadian rekleks nasokardiak yang disebabkan karena pemasangan selang nasogastrik.

\section{LAPORAN KASUS}

Seorang pasien laki-laki berusia 46 tahun dengan pneumonia dan tuberkulosis paru dirawat di bangsal penyakit dalam. Pasien tersebut mendapatkan terapi antibiotik kombinasi dan obat bronkodilator. Tidak ada riwayat penyakit dahulu dan riwayat penyakit keluarga sebelumnya. Pada hari ke-20 perawatan, pasien tiba-tiba mengalami sesak napas yang memberat dan terjadi penurunan saturasi oksigen.

Pada pemeriksaan awal, saluran napas tampak bebas, frekuensi napas 30 kali per menit, saturasi oksigen menunjukkan angka 90-95\% dengan terapi oksigen $15 \mathrm{lpm}$ menggunakan non-rebreathing mask. Tekanan darah pasien 100/60 $\mathrm{mmHg}$, frekuensi denyut jantung 120 kali per menit, dan Glasgow Coma Scale (GCS) E4 M6 V3. Pada pemeriksaan fisik lanjutan ditemukan adanya ronki di seluruh lapang kedua paru. Pemeriksaan analisa gas darah yang dilakukan sebelum pemeriksaan awal tim medis menunjukkan hasil $\mathrm{pH} 7,33, \mathrm{pCO}_{2} 56,1$ $\mathrm{mmHg}, \mathrm{pO}_{2} 41,7 \mathrm{mmHg}, \mathrm{HCO}_{3}-30,1 \mathrm{mEq} / \mathrm{L}$, BE 3,7 mEq/L, Saturasi $O_{2} 68,1 \%$. Selanjutnya, pasien dipersiapkan untuk dipindahkan ke ruang perawatan intensif.

Pada persiapan transfer, direncanakan tindakan pemasangan selang nasogastrik untuk mencegah aspirasi. Selang nasogastrik berukuran 16G dipasang melalui rongga hidung dengan blind technique didahului dengan pemberian xylocaine jelly pada selang. Pada proses pemasangan selang nasogastrik di $5 \mathrm{~cm}$ pertama, pasien mengalami gasping dan bradikardia, tekanan darah tidak terdeteksi, dan terjadi penurunan kesadaran pada pasien. Prosedur pemasangan selang nasogastrik segera dihentikan. Pemasangan oropharyngeal airway (OPA) segera dilakukan dan dilanjutkan dengan pemberian ventilasi manual menggunakan bag valve mask. Atropin sulfas dengan dosis $0,5 \mathrm{mg}$ dan norepinefrin dengan dosis $0,3 \mathrm{mcg} / \mathrm{kgBB} /$ menit juga diberikan pada pasien disaat yang bersamaan. Setelah penanganan kegawatdaruratan dilakukan, saturasi oksigen pasien kembali ke angka 95\% dengan oksigen $15 \mathrm{lpm}$, tekanan darah kembali ke 120/60 mmHg, frekuensi nadi $110 \mathrm{x} /$ menit, dan GCS E1 M4 V3. Tiga puluh menit kemudian, tanda vital pasien kembali ke keadaan awal dan pemberian norepinefrin dihentikan secara bertahap. Setelah pasien stabil, pasien segera dipindahkan ke ruang perawatan intensif.

\section{PEMBAHASAN}

Pada pasien yang mengalami refleks nasokardiak, terjadi perubahan cepat dari sistem kardiovaskular yang memperburuk kondisi pasien. Terdapat keterbatasan pada proses mendiagnosis refleks nasokardiak karena adanya kesulitan untuk mendefinisikan kejadian ini. Para ahli menggunakan istilah trigeminokardiak refleks (TCR) untuk menjelaskan kejadian ini. Sebelumnya, kejadian TCR lebih dikenal dengan okulokardiak refleks. ${ }^{1,4}$ TCR adalah kejadian klinis yang meliputi adanya perubahan cepat kepada perburukan hemodinamik (tekanan darah dan frekuensi denyut jantung), perubahan pernapasan (apnea), dan perubahan pada gaster (hypermotility) yang disebabkan karena adanya stimulasi dari cabang nervus trigeminus. 
Terdapat dua kriteria mayor dan dua kriteria minor untuk refleks ini. Kriteria mayor adalah adanya penjelasan terhadap kejadian yang terjadi dan sifatnya reversibel. Kriteria minor untuk TCR adalah adanya pencegahan dan pengulangan untuk kejadian yang terjadi. Penjelasan terhadap kejadian perubahan hemodinamik yang dimaksud pada kriteria mayor adalah keharusan adanya rangsangan terhadap nervus trigeminus yang adekuat. Reversibilitas yang terjadi pada fenomena ini adalah adanya perbaikan hemodinamik yang terjadi setelah stimulus dihentikan. Kriteria minor yang disebutkan diatas tidak harus terjadi pada pasien. Pengulangan yang dimaksud pada kriteria minor adalah adanya perubahan fisiologis yang terjadi berulang saat terdapat stimulus yang serupa. Pencegahan dapat digunakan saat TCR sedang tidak terjadi dan saat adanya blok nervus trigeminus dan/atau saat pemberian obat-obatan antikolinergik. Kesimpulannya, stimulus yang lebih lemah akan menyebabkan efek yang lebih ringan. ${ }^{5}$

Patofisiologi terjadinya refleks nasokardiak dimulai dari adanya rangsangan pada cabang nervus trigeminus di rongga hidung yang kemudian diteruskan ke pars kaudalis dari nukleus spinalis nervus trigeminus melalui ganglion Gasseri. Rangsang kemudian diteruskan ke sistem saraf pusat pada rostral ventrolateral medulla dan nukleus parabrakialis lateralis. Jaras eferen dari pusat menuju ke saraf spinalis dan menuju nervus vagus yang kemudian memberikan efek inhibisi terhadap jantung. ${ }^{6}$

Pada kasus ini, kriteria mayor untuk menjelaskan kejadian TCR pada pasien adalah adanya pemasangan selang nasogastrik yang dapat menyebabkan perangsangan pada cabang nervus trigeminus pada daerah rongga hidung. Nervus trigeminus memiliki cabang saraf sensoris dan motorik dan terbagi menjadi tiga cabang utama, dimana beberapa diantaranya berada pada dinding rongga hidung. Bagian medial rongga hidung dipersarafi oleh cabang nervus oftamikus (V1) dan nervus maksilaris (V2) dari nervus trigeminus. Nervus V1 mempersarafi bagian anterosuperior dari septum nasi dan bagian anterosuperior dari dinding lateral rongga hidung. Nervus V2 mempersarafi bagian posterosuperior-inferior dari dinding lateral rongga hidung. Selang nasogastrik dapat merangsang saraf yang berada pada rongga hidung tesebut dan merangsang timbulnya refleks nasokardiak. Devakumari dkk melaporkan adanya kasus TCR yang terjadi pada operasi maksilofasial, terutama operasi yang sifatnya

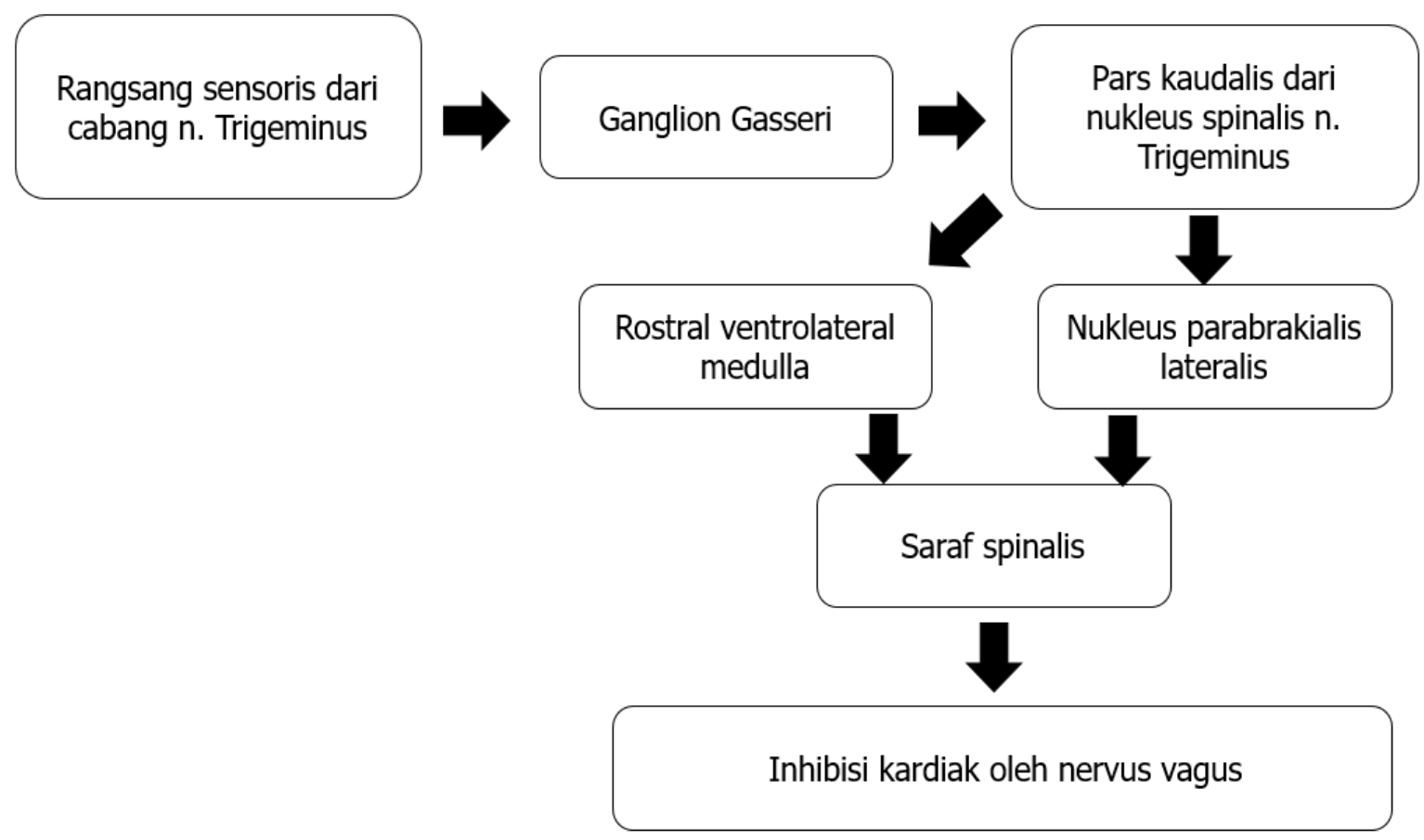

Gambar1. Patofisiologi terjadinya refleks nasokardiak 
mayor, namun beberapa kasus dilaporkan pada operasi yang sifatnya minor seperti ekstraksi gigi. ${ }^{4}$ Terdapat dua kejadian refleks nasokardiak yang berhubungan dengan pemasangan selang nasogastrik. Kejadian ini dilaporkan oleh Haldar dkk. pada tahun 2015 dan Fujiwara dkk. pada tahun 2017.7,8 Haldar dkk melaporkan adanya refleks nasokardiak dengan adanya perubahan tekanan pada selang nasogastrik dengan dilakukannya tindakan aspirasi dan tindakan injeksi pada selang nasogastrik. ${ }^{7}$

Mekanisme terjadinya refleks nasokardiak dimulai dengan adanya rangsangan terhadap saran V1 dan V2 dari cabang nervus trigeminus yang memberikan sinyal ke ganglion Gasserian yang terdapat pada ventrikel keempat sebagai jalur aferennya. Jalur eferen melanjutkan stimulus dari jalur aferen ke nukleus motorik nervus vagus melalui serabut internukleus pada formasio retikularis. Rangsangan ini memberikan efek kronotropik negatif dan inotropik negatif yang menyebabkan timbulnya bradikardia dan penurunan tekanan darah. ${ }^{4}$ Teori yang saat ini berkembang menyatakan adanya efek simpatis seperti efek vasodilatasi dari pembuluh darah serebral dan hipertensi. ${ }^{4,7}$

Efek reversibel dapat dilihat dengan kembalinya hemodinamik pasien ke normal. Pada kasus ini, pasien diberikan $0,5 \mathrm{mg}$ atropin sulfas dan 0,3 $\mathrm{mcg} / \mathrm{kgBB} /$ menit norepinefrin. Norepinefrin diberikan untuk meningkatkan tekanan darah dan dosisnya diturunkan bertahap dengan cepat. Banyak pembahasan yang membahas tentang tatalaksana terbaik untuk TCR. Pemberian atropin sulfas bukan satu-satuya pilihan. Hal paling penting dalam penanganan TCR adalah kesadaran akan adanya potensi bahaya dan meminimalisir stimulasi saraf. Injeksi atropin sulfas intravena dapat digunakan untuk mencegah timbulnya TCR pada kondisi tertentu. Sebelumnya ada penelitian yang mempelajari mengenai efikasi dari atropin sulfas IV dan glycopirrolate untuk mencegah okulokardiak refleks pada pasien anak yang menjelani operasi strabismus. Penelitian ini menggunakan 2 dosis yang berbeda untuk atropin sulfas (10 dan 15 $\mathrm{mcg} / \mathrm{kgBB}$ ) dan glycopirrolate (5 dan 7,5 mcg/ kgBB). Hasil penelitian menunjukan adanya penurunan kejadian bradikardia sampai $23,8 \%$ dan $33,3 \%{ }^{6}$

Tatalaksana yang menjadi kunci dalam penanganan TCR adalah penghentian semua prosedur penyebab dan mempertimbangkan pemberian atropin sulfas $0,5 \mathrm{mg}$ secara intravena. Dosis obat dapat diulang jika TCR menetap. Prabhakar dkk. melaporkan kasus seorang wanita 48 tahun yang mengalami bradikardi dan hipotensi yang berat saat prosedur kraniotomi. Pasien tidak respons dengan pemberian atropin namun berhasil ditangani dengan pemberian epinefrin. Cara kerja adrenalin adalah dengan meningkatkan resistensi perifer melalui adrenoreseptor alfa-1 yang berefek meningkatkan frekuensi denyut nadi dan volume sekuncup. ${ }^{9}$ Kasus-kasus dengan nasokardiak refleks melaporkan kemungkinan adanya kasus TCR yang refrakter terhadap atropin sulfas dan obat vagolitik lainnya, sehingga penggunaan epinefrin dapat dipertimbangkan sebagi terapi pada kasus-kasus ini.

Ada beberapa faktor yang dapat meningkatkan risiko terjadinya refleks ini. Teori yang berkembang adalah adanya proteksi fisiologis endogen dari otak sebagai respon terhadap kondisi iskemik. Refleks ini adalah usaha tubuh untuk menjaga oksigenasi, namun efek yang berelebih akan menimbulkan bahaya pada pasien. ${ }^{5}$ Risiko tinggi timbulnya nasokardiak refleks terdapat pada anak-anak, jenis kelamin laki-laki, kondisi peningkatan aktivitas simpatis, hipoksemia, hiperkarbia, anestesia dangkal, penggunaan pelumpuh otot, penggunaan opioid, penggunaan beta-bloker, dan intensitas stimulus. Kasus yang dibahas pada laporan kasus ini menunjukkan seorang pasien laki-laki dalam kondisi hipoksia dan hiperkarbia akibat kondisi gagal napas yang dialaminya karena infeksi paruparu.

\section{SIMPULAN}

Pemasangan selang nasogastrik pada pasien dengan risiko tinggi harus dilakukan secara hati-hati karena dapat memicu kejadian nasokardiak refleks. Peralatan gawat darurat dasar seperti monitor non-invasive dan obatobatan emergensi harus dipersiapkan pada prosedur pemasangan selang nasogastrik pasien risiko tinggi. Intubasi dilakukan pada pasien untuk memaksimalkan penghantaran oksigen ke jaringan. Penelitian lebih lanjut tentang nasokardiak refleks diperlukan untuk membahas fenomena ini. 


\section{KONFLIK KEPENTINGAN}

Penulis menyatakan tidak ada konflik kepentingan dalam penulisan artikel ini.

\section{DAFTAR PUSTAKA}

1. Gehdoo RP. Post operative pain management iBaxandall ML,Thorn JL. The Nasocardiac Reflex. Anaesthesia. 1988; 43: $480-1$.

2. Meuwly C, Chowdhury T, Sandu N, Golanov E, Erne P, Rosemann T and Schaller B. Definition and Diagnosis of the Trigeminocardiac Reflex: A Grounded Theory Approach for an Update. Front. Neurol. 2017;8:533.

3. Prabhakaran S, Doraiswamy VA, Nagaraja V, Cipolla J, Ofurum U, Evans DC et al. Nasoenteric tube complication. Sca J Surg. 2012; 101:147 - 55.

4. Devakumari MDS, Vijhayapriya MS. Trigemino Cardiac Reflex and Its Importance in Maxillofacial Surgery- A Revie". IOSR Journal of Dental and Medical Sciences. 2013;12: $7-11$.

5. Meuwly C, Golanov E, Chowdhury T, Erne P, Schaller B. Trigeminal Cardiac Reflex: New Thinking Model About the Definition Based on a Literature Review. Medicine. 2015; 94(5).

6. Schaller, B. Trigeminocardiac reflex. Journal of Neurology. 2004;251(6).

7. Haldar R, Kaur J, Sukhminder J. Nasocardiac reflex during aspiration and injection through a nasogastric tube: An infrequent occurrence. Ind J Crit Care Med. 2015; 19(4).

8. Fujiwara $Y$, Kishimoto $T$, Hirabayashi $M$, Doi K. A Case of Severe Bradycardia during Insertion of a Nasogastric Tube. Jpn Soc Clin Anesth. 2017; 37:1.

9. Prabhakar H, Rath GP, Arora R. Sudden cardiac standstill during skin flap elevation in a patient undergoing craniotomy. J Neurosurg Anesthesiol. 2007;19:203 - 20. 